\section{(6) OPEN ACCESS}

\title{
Spectrum of cardiac disease in maternity in a low-resource cohort in South Africa
}

\author{
Karen Sliwa, ${ }^{1,2,3,4}$ Elena Libhaber, ${ }^{4}$ Catherine Elliott, ${ }^{5}$ Zoe Momberg, ${ }^{5}$ \\ Ayesha Osman, ${ }^{5}$ Liesl Zühlke, ${ }^{3,6}$ Tony Lachmann, ${ }^{5}$ Lauren Nicholson, ${ }^{1}$ \\ Friedrich Thienemann, ${ }^{2,7}$ Jolien Roos-Hesselink, ${ }^{8}$ John Anthony ${ }^{5}$
}

For numbered affiliations see end of article.

\section{Correspondence to} Professor Karen Sliwa, Department of Medicine, Hatter Institute for

Cardiovascular Research in Africa, Groote Schuur Hospital, University of Cape Town, Cape Town 7935, South Africa; Karen.Sliwa-Hahnle@uct.ac.za

Received 30 May 2014 Revised 8 August 2014 Accepted 10 August 2014 Published Online First 16 September 2014

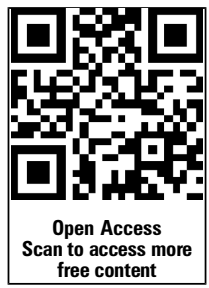

\section{SLinked}

- http://dx.doi.org/10.1136/ heartjnl-2014-306367

\section{CrossMark}

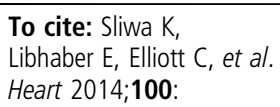

\section{ABSTRACT}

Background Lack of evidence-based data on the spectrum of cardiovascular disease (CVD) in pregnancy or in the postpartum period, as well as on maternal and fetal outcome, provides challenges for treating physicians, particularly in areas of low resources. The objectives of this study were to investigate the spectrum of disease, mode of presentation and maternal and fetal outcome of patients referred to a dedicated Cardiac Disease and Maternity Clinic (CDM).

Methods The prospective cohort study was conducted at a single tertiary care centre in South Africa. Two hundred and twenty-five women presenting with CVD in pregnancy, or within 6 months postpartum, were studied over a period of 2 years. Clinical assessment, echocardiography and laboratory tests were performed at baseline and follow-up visits. Prepartum, peripartum and postpartum complications were grouped into cardiac, neonatal and obstetric events.

Results Ethnicity was black African (45\%), mixed ethnicity (32\%), white (15\%), Indian/others (8\%) and $12 \%$ were HIV positive. Of the 225 consecutive women (mean age 28.8 56.4 ), 196 (86.7\%) presented prepartum and 73 in modified WHO class I. The 152 women presenting in a higher risk group (modified WHO class II-IV) were offered close follow-up at the CDM clinic and were diagnosed with congenital heart disease $(32 \%, 15$ operated previously), valvular heart disease $(26 \%, 15$ operated previously), cardiomyopathy (27\%) and other (15\%). Women presenting with symptoms of CVD or heart failure postpartum $(n=30)$ presented in a higher New York Heart Association, had higher heart rates $(p<0.001)$ and NTproBNP levels $(p<0.0005)$. Of the 152 patients, $9(6 \%)$ died within the 6-month follow-up period. Eight of the nine patients died $>42$ days postpartum. Perinatal death occurred in $1 / 152(0.7 \%)$ - translating to a perinatal mortality rate of $7 / 1000$ live births.

Conclusions Disease patterns were markedly different to that seen in the developed world. However, joint obstetriccardiac care in the low-resource cohort was associated with excellent survival outcome rates of pregnant mothers (even with complex diseases) and their offspring and was similar to that seen in the western world. Mortality typically occurred in the postpartum period, beyond the standard date of recording maternal death.

\section{INTRODUCTION}

There is generally a paucity of data describing cardiovascular disease (CVD) in women from Africa or other developing regions. In particular, few data describe CVD related to pregnancy with its unique disease patterns and presentations. ${ }^{1}{ }^{2}$ This has to be seen in the context of a general shortage of physicians in Africa; for example, South Africa has only 165 registered cardiologists for a population of 50 million. In April 2010, a dedicated weekly 'Cardiac Disease and Maternity Clinic (CDM)' was established at the Division of Cardiology, Department of Medicine, Groote Schuur Hospital, University of Cape Town, to provide multidisciplinary systematic care for women with suspected or previously known CVD, presenting in pregnancy or postpartum. In July 2010, a prospective singlecentre study was initiated, which aimed to investigate the spectrum of CVD presenting prepartum or postpartum, as well as the maternal and fetal outcome using a comprehensive system of care by a team of obstetricians, anaesthesiologists and cardiologists.

\section{METHODS}

\section{Study design}

Between 1 July 2010 and 30 June 2012, 225 consecutive patients with suspected or previously diagnosed CVD, including blood pressure and heart rate, were assessed at first visit to the joint cardiacobstetric clinic, having been sent there via a referral algorithm from primary care and secondary care facilities in Cape Town and from within the tertiary hospital (figure 1). Risk stratification after hours or via the emergency room were included and assessed in the wards or at the next available clinic date. The study was approved by the Ethics Committee of the University of Cape Town (HEC ref: 173/ 2010).

All patients referred to this clinic were seen jointly by a senior cardiology and obstetric consultant and physicians from other disciplines, for example, radiology, endocrinology and anaesthetics, were consulted. Patients were managed jointly throughout their pregnancy and those presenting postpartum were seen once at this clinic and managed further at the general cardiac clinic or a dedicated cardiomyopathy clinic, Groote Schuur Hospital (KS). Patients were booked according to standard management, which could include a waiting period of up to 3 months.

\section{Data}

Baseline data recorded at the first visit included sociodemographic factors, family history of CVD, 
Figure 1 Referral algorithm to joint Cardiac Maternity Clinic, Groote Schuur Hospital. BMI, body mass index; BP, blood pressure; ESC, European Society of Cardiology; ASD, atrial septal defect; VSD, ventricular septal defect; NYHA FC, New York Heart Association Functional Class; PPCM, peripartum cardiomyopathy; $\mathrm{RHD}$, rheumatic heart disease; HT, hormone therapy; $\mathrm{AV}$, aortic valve.

\section{Referral Algorithm for suspected and previously known Cardiovascular Disease in Maternity (CDM)}

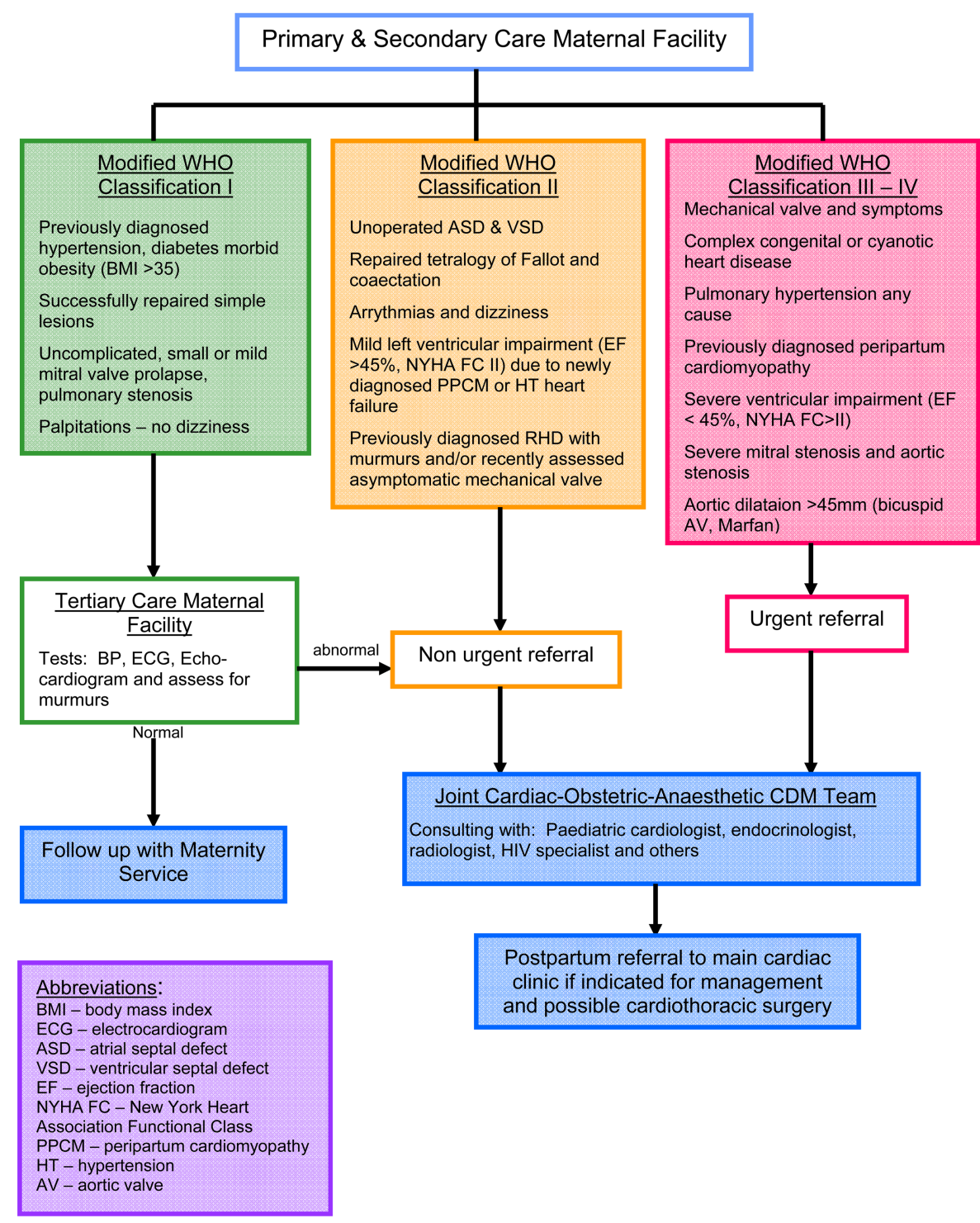

history of pre-eclampsia or chronic hypertension, HIV status, onset of symptoms and signs, parity, prior cardiac events, prior surgery or cardiac interventions and use of medication. In addition, New York Heart Association Functional Class (NYHAFC), ECG and transthoracic echocardiography (KS) were recorded, including assessments of left and right ventricular function, Doppler quantification of inflow and outflow obstruction, quantification of valvular regurgitation and systolic pulmonary artery pressure were measured according to standard practice guidelines. $^{3}$ The EF was calculated according to standard criteria, usually using M-mode and, in some cases, applying the modified Simpson method. ${ }^{3}$

Patients were stratified into four risk groups using a modified WHO risk classification for pregnant women with cardiac disease. Depending on diagnosis and severity of disease, risk classification ranged from class I (low risk) to class IV (contraindication for pregnancy), as recently used in the European Society of Cardiology (ESC) Guidelines on the management of CVD during pregnancy. ${ }^{4}$ Diseases not accounted for by this classification were scored by two authors, a cardiologist (KS) and an obstetrician (JA). The modified WHO classification has a prediction value in the management of pregnant women but is also based on the underlying severity of heart disease; uniformity in the classification has been secured by applying this classification to both antenatal and postpartum patients.

Poor outcome was as previously defined, ${ }^{5}$ using a combined endpoint of death, EF $<45 \%$ or remaining in NYHA FC III/IV as the cohort was relatively small.

Patients with a history of CVD (but no symptoms or signs) and a normal clinical examination, together with absent or minimal echocardiography changes-such as operated congenital heart disease (CHD) or a prior history of rheumatic fever without clinical sequelae-were only seen once and then referred to secondary-level obstetric care. These patients were classified as modified WHO stage I. As many of those patients were referred from peripheral hospitals, records were not available to document maternal and fetal outcomes.

Patients with symptoms, signs or a WHO stage II-IV classification had clinical visits during the second trimester ( $<28$ weeks), third trimester ( $28-37$ weeks), peripartum period (onset of labour until hospital discharge) and at 6 weeks and 6 months postpartum. The frequency of visits was adapted to 
the severity of the disease and transport logistics of the patient. For many women, frequent hospital visits are not affordable. Mode of delivery, use of tocolytic therapy and perinatal outcome were obtained from patients, referring physicians and by examining the obstetric records. Newborns of mothers with CHD underwent paediatric echocardiography.

Peripartum complications were grouped into cardiac, neonatal and obstetric events. Cardiac events were defined by (re)admission for heart failure, symptomatic tachycardia requiring therapy, arrhythmia, stroke and cardiac death. Neonatal events were defined as any of the following: premature birth ( $<37$ weeks gestation), small-for-gestational age birthweight $(<10$ th centile), respiratory distress syndrome, intraventricular haemorrhage, fetal death ( $>20$ weeks' gestation) or neonatal death (within 28 days after birth). Perinatal mortality rates were calculated based on the number of fetal deaths and early neonatal deaths per 1000 live births. Obstetric events that were documented included non-cardiac death, pregnancy-induced hypertension, pre-eclampsia and postpartum haemorrhage (PPH). PPH was defined as blood loss $>500 \mathrm{~mL}$ (vaginal delivery) or $>1000 \mathrm{~mL}$ (caesarean section), which required transfusion or was accompanied by a drop in haemoglobin $>2.0 \mathrm{~g} / \mathrm{L}$.

\section{Blood tests}

Routine laboratory workup on all patients included a haemoglobin and HIV test. Other blood tests, as determined by the physician, were performed in certain cases. Plasma was collected at baseline and, in consenting patients, also postdelivery. Aliquots were stored at $-80^{\circ} \mathrm{C}$ for future analysis. Plasma NT-proBNP was measured by electrochemiluminescence immunoassay (BNP Fragment EIA, BIOMEDICA GRUPPE gmbHa Co, Vienna, Austria). ${ }^{6}$

\section{Data collection}

Data were entered into a specifically developed web-based platform for this project, which included uploading of ECGs in PDF or jpeg format and echo-images as still pictures or in AVI mode.

\section{Statistical analysis}

Cardiac, neonatal and obstetric events were analysed separately. Database management and statistical analyses were performed with SAS software, V.9.2 statistical program (SAS, Institute, Cary, North Carolina, USA). Continuous data were expressed as mean \pm SD or median (range). Comparison of means and proportions between subgroups at baseline was performed by independent $\mathrm{t}$ test and $\chi^{2}$ statistics (or Fisher's exact test where necessary), respectively, and where data were not normally distributed, a Wilcoxon rank-sum test was used.

Univariate and stepwise multiple logistic regression analyses were performed to establish independent predictors of poor outcome. Significance was assumed at a two-sided value of $\mathrm{p}<0.05$.

Table 1 Baseline maternal characteristics of 225 cohorts presenting in modified WHO I-IV

\begin{tabular}{|c|c|c|c|c|}
\hline & All patients $(n=225)$ & WHO I (n=73) & WHO II-IV (n=152) & p Value \\
\hline Age at enrolment (years) & $28.6 \pm 6.4$ & $28.8 \pm 7.0$ & $28.5 \pm 6.1$ & 0.97 \\
\hline \multicolumn{5}{|l|}{ Ethnicity, n (\%) } \\
\hline African or black & $101(45)$ & $23(32)$ & $79(52)$ & $<0.0001$ \\
\hline Mixed & $72(32)$ & $15(20)$ & $56(37)$ & \\
\hline White & $34(15)$ & $19(26)$ & $15(10)$ & \\
\hline Other (Arab, Indian, other) & $18(8)$ & $16(22)$ & $2(1)$ & \\
\hline \multicolumn{5}{|l|}{ General medical history, n (\%) } \\
\hline Chronic hypertension & $12(5)$ & $2(3)$ & $10(7)$ & 0.35 \\
\hline Hypercholesterolaemia & $3(1)$ & $0(0)$ & $3(2)$ & 0.55 \\
\hline HIV & $38(12)$ & $2(3)$ & $36(24)$ & $<0.0001$ \\
\hline Syphilis & $1(0.4)$ & $0(0)$ & $1(1)$ & 1.00 \\
\hline Tuberculosis & $4(2)$ & $0(0)$ & $4(3)$ & 0.31 \\
\hline \multicolumn{5}{|c|}{ Clinical history and presentation, $\mathrm{n}(\%)$} \\
\hline Previously known CVD & $93(41)$ & $40(55)$ & $53(35)$ & 0.006 \\
\hline Previously operated CVD & $57(25)$ & $27(37)$ & $30(20)$ & 0.007 \\
\hline NYHA FC I-II & $193(86)$ & $73(100)$ & $120(79)$ & $<0.0001$ \\
\hline NYHA FC III-IV & $32(14)$ & $0(0)$ & $32(21)$ & \\
\hline $\mathrm{SBP}$ in $\mathrm{mmHg}$ & $119 \pm 15$ & $118 \pm 13$ & $119 \pm 16$ & 0.97 \\
\hline $\mathrm{DBP}$ in $\mathrm{mm} \mathrm{Hg}$ & $74 \pm 11$ & $75 \pm 10$ & $74 \pm 11$ & 0.53 \\
\hline Heart rate in bpm & $86 \pm 18$ & $78 \pm 12$ & $90 \pm 19$ & $<0.0001$ \\
\hline Weight in kg & $72.1 \pm 16.8$ & $72.5 \pm 12.5$ & $72.1+18.6$ & 0.30 \\
\hline \multicolumn{5}{|l|}{ Obstetric history, n (\%) } \\
\hline Gestational age at presentation & $\mathrm{n}=188$ & $n=66$ & $n=122$ & \\
\hline$<12$ weeks & $7(4)$ & $3(5)$ & $4(3)$ & \\
\hline 12-24 weeks & $84(45)$ & $32(48)$ & $52(43)$ & 0.65 \\
\hline$>24$ weeks & $97(52)$ & $31(47)$ & $66(54)$ & \\
\hline Gravida (median, range) & $2(1-7)$ & $2(1-6)$ & $2(1-7)$ & 0.0002 \\
\hline Para (median, range) & $1(0-5)$ & $1(0-4)$ & $1(0-5)$ & 0.003 \\
\hline Nulliparous, n (\%) & $65(29)$ & $29(40)$ & $36(24)$ & 0.02 \\
\hline Twin pregnancies & $3(1)$ & $0(0)$ & $3(2)$ & 0.30 \\
\hline
\end{tabular}




\section{RESULTS}

The characteristics of the 225 patient cohort is shown in table 1 .

Black patients presented significantly more frequently with advanced disease (WHO II-IV) compared with other ethnic groups $(p<0.0001)$. There were significant differences in heart rate, gravidity and parity in patients presenting with a diagnosis in the modified WHO class I versus those in class II-IV. Generally, comorbidity, including HIV infection, was associated with more severe cardiac disease, measured in terms of WHO classification $(p<0.0001)$. Patients with a high-risk category defined by modified WHO class presented with more symptomatic disease, defined by the NYHAFC and a higher heart rate $(\mathrm{p}<0.0001)$.

\section{Diagnosis}

The diagnosis of women classified as WHO class I $(n=73)$ fell into one of four categories: history of rheumatic heart disease (RHD) or minor RHD lesion $(n=16 ; 22 \%)$, minor or operated CHD with no significant residual structural abnormality $(n=26$; $35 \%)$, chronic hypertension with no end-organ damage $(n=4$; $7 \%$ ) or they had been referred for other reasons such as history of palpitations or the need for preconception counselling $(n=27 ; 36 \%)$. Diagnoses of the 152 patients presenting in WHO class II-IV and needing close follow-up were CHD (32\% -ventricular septum defect $n=6$; atrial septum defect $n=8$; coarctation $\mathrm{n}=3$ and others; only 15 operated previously), RHD (26\%, 15 operated previously) and cardiomyopathy $(27 \%$ -11 had idiopathic dilated cardiomyopathy; 21 peripartum cardiomyopathy (PPCM) and 9 hypertension-related cardiomyopathy). Fifteen per cent had other diagnosis such as Takayasu's disease $(n=4)$, Marfan's disease $(n=4)$, ventricular arrhythmias $(n=5)$, constrictive pericarditis $(n=3)$ and others. None of the women presented with ischaemic heart disease.

\section{Demographics, medical and obstetric history of patients presenting in WHO II-IV needing follow-up}

Table 2 shows ethnic group/ethnicity defined by language, educational level, disposable income, general medical history (including smoking), cardiac and obstetric history for patients presenting prepartum or postpartum. One hundred and twentytwo women (80\%) presented prepartum with 66 (54\%) patients presenting for the first time to our clinic with a gestational age at entry of $>24$ weeks. Black patients were represented in a higher percentage in the postpartum cohort $(p=0.009)$. Patients in modified WHO class II-IV had significantly higher gravidity $(p=0.0002)$. Women presenting in the postpartum period $(n=30)$ presented with more advanced NYHA $(p<0.001)$ and had a significantly higher heart rate $(\mathrm{p}<0.001)$ and NTproBNP $(\mathrm{p}<0.0001)$.

Presenting symptoms, laboratory tests, ECG, echocardiographic findings and medication are shown in table 3. Patients developing symptoms postpartum presented with significantly larger left ventricular dimensions and with a markedly lower echocardiography EF $(44.7 \pm 11.8$ vs $54.5 \pm 12.4$, p $<0.003)$.

Of the women diagnosed with CVD prepartum, $27 \%$ received diuretics, $7.3 \%$ beta-blockers and $7.3 \%$ warfarin while pregnant (table 3 ).

\section{Overall and cardiac outcome}

Only one patient of the diagnosed prepartum women had no postpartum visit. Thus, 142 patients had follow-up data.

Maternal mortality rate was 9/152: 5.92\%, 95\% CI $(2.15 \%$ to $9.65 \%$ ) within the 6-month postpartum follow-up period.
Table 2 Baseline characteristics: demographics and medical history modified WHO II-IV

\begin{tabular}{|c|c|c|c|}
\hline & $\begin{array}{l}\text { All } \\
\text { patients } \\
(n=152)\end{array}$ & $\begin{array}{l}\text { Presenting } \\
\text { prepartum } \\
(n=122)\end{array}$ & $\begin{array}{l}\text { Presenting } \\
\text { postpartum } \\
(n=30)\end{array}$ \\
\hline Age at enrolment (years) & $28.5 \pm 6.1$ & $28.2 \pm 6.2$ & $29.6 \pm 5.8$ \\
\hline \multicolumn{4}{|l|}{ Ethnicity, n (\%) } \\
\hline African or black & $79(52)$ & $55(45)$ & $24(80)^{*}$ \\
\hline Mixed & $56(37)$ & $50(41)$ & $6(20)^{*}$ \\
\hline White & $15(10)$ & $15(12)$ & $0(0)$ \\
\hline Other (Arab, Indian, other) & $2(1)$ & $2(2)$ & $0(0)$ \\
\hline \multicolumn{4}{|l|}{ Language, n (\%) } \\
\hline Afrikaans & $43(28)$ & $40(33)$ & $3(10)$ \\
\hline English & $33(22)$ & $29(24)$ & $4(13)$ \\
\hline isiXhosa & $58(38)$ & $41(34)$ & $17(57)$ \\
\hline isizulu & $12(8)$ & $9(7)$ & $3(10)$ \\
\hline Other & $6(4)$ & $3(2)$ & $3(10)$ \\
\hline \multicolumn{4}{|l|}{ Education level, n (\%) } \\
\hline No school & $1(1)$ & $0(0)$ & $1(3)$ \\
\hline Year 1-7 & $46(30)$ & $36(30)$ & $10(33)$ \\
\hline Year 8-11 & $92(61)$ & $73(60)$ & $19(63)$ \\
\hline Year 12/>Year 12 & $13(8)$ & $13(10)$ & 0 \\
\hline \multicolumn{4}{|l|}{ Income per month, $\mathrm{n}(\%)$ (ZAR) } \\
\hline$<300$ & $56(37)$ & $39(33)$ & $17(57)$ \\
\hline 300-999 & $38(25)$ & $31(26)$ & $7(23)$ \\
\hline 1000-9999 & $54(36)$ & $48(40)$ & $6(20)$ \\
\hline$\geq 10000$ & $2(1)$ & $2(2)$ & $0(0)$ \\
\hline \multicolumn{4}{|l|}{ General medical history (\%) } \\
\hline Chronic hypertension & $10(7)$ & $10(8)$ & $0(0)$ \\
\hline Hypercholesterolaemia & $3(2)$ & $3(2)$ & $0(0)$ \\
\hline HIV & $36(24)$ & $26(21)$ & $10(33)$ \\
\hline Syphilis & $1(1)$ & $1(1)$ & $0(0)$ \\
\hline Tuberculosis & $4(3)$ & $3(2)$ & $1(3)$ \\
\hline Family history of CVD & $23(15)$ & $21(17)$ & $2(7)$ \\
\hline Family history of PPCM/CMO & $11(7)$ & $10(8)$ & $1(3)$ \\
\hline Heart valve replacement/repair & $16(11)$ & $16(13)$ & $0(0)$ \\
\hline \multicolumn{4}{|l|}{ Obstetric history, n (\%) } \\
\hline \multicolumn{4}{|c|}{ Gestational age at presentation, women presenting prepartum } \\
\hline 12-24 weeks & $52(43)$ & $52(43)$ & 0 \\
\hline$>24$ weeks & $66(54)$ & $66(54)$ & 0 \\
\hline Nulliparous n (\%) & $36(24)$ & $32(26)$ & $4(13)$ \\
\hline Parous n (\%) & $116(76)$ & $90(74)$ & $26(87)$ \\
\hline \multicolumn{4}{|l|}{ Social history, $\mathrm{n}(\%)$} \\
\hline \multicolumn{4}{|l|}{ Smoking } \\
\hline Current & $10(6)$ & $8(7)$ & $2(7)$ \\
\hline Former & $2(1)$ & $2(2)$ & $0(0)$ \\
\hline \multicolumn{4}{|l|}{ Alcohol use } \\
\hline Current & $3(2)$ & $1(1)$ & $2(7)$ \\
\hline Former & $2(1)$ & $2(2)$ & $0(0)$ \\
\hline
\end{tabular}

The diagnoses of women who died were familial and PPCM $(n=7)$ and two cases of prosthetic valve complications (thrombosis and sepsis) (table 4). All patients who died belonged to the mod WHO class III or IV risk group. Eight of the nine patients died after 42 days of postpartum. Thirty women had poor outcome as predefined using a combined endpoint of death, EF and FC.

Of the women that were diagnosed prepartum, 34\% developed signs and symptoms of heart disease while pregnant, 
Table 3 Symptoms, examination and medication at presentation for patients in modified WHO II-IV

\begin{tabular}{|c|c|c|c|c|}
\hline & All patients $(n=152)$ & Presenting prepartum $(n=122)$ & Presenting postpartum $(n=30)$ & $\mathrm{p}$ Value \\
\hline \multicolumn{5}{|c|}{ Symptoms and severity of disease, $\mathrm{n}(\%)$} \\
\hline Palpitations & $64(42)$ & $54(44)$ & $10(33)$ & 0.27 \\
\hline Presyncope/syncope & $1(0)$ & $1(0)$ & $0(0)$ & 0.58 \\
\hline Chest pain & $5(3)$ & $4(3)$ & $1(3)$ & 1.00 \\
\hline \multicolumn{5}{|l|}{ NYHA FC } \\
\hline I/II & $120(79)$ & $108(89)$ & $12(40)$ & $<0.001$ \\
\hline III & $32(21)$ & $14(11)$ & $18(60)$ & $<0.001$ \\
\hline \multicolumn{5}{|l|}{ Modified WHO group } \\
\hline II-III & $98(64)$ & $98(80)$ & $0(0)$ & $<0.001$ \\
\hline IV & $54(36)$ & $24(20)$ & $30(100)$ & $<0.001$ \\
\hline \multicolumn{5}{|l|}{ Vital signs } \\
\hline Heart rate in bpm & $90 \pm 19$ & $87 \pm 17$ & $103 \pm 19$ & $<0.0001$ \\
\hline $\mathrm{SBP}$ in $\mathrm{mm} \mathrm{Hg}$ & $119 \pm 16$ & $121 \pm 15$ & $111 \pm 17$ & 0.001 \\
\hline $\mathrm{DBP}$ in $\mathrm{mm} \mathrm{Hg}$ & $74 \pm 11$ & $74 \pm 12$ & $74 \pm 11$ & 0.79 \\
\hline \multicolumn{5}{|l|}{ Physical examination, n (\%) } \\
\hline Jugular venous pressure $>5$ & $42(28)$ & $20(16)$ & $22(73)$ & $<0.001$ \\
\hline Crepitations & $40(26)$ & $21(18)$ & $19(63)$ & $<0.001$ \\
\hline Oedema & $29(19)$ & $15(12)$ & $14(47)$ & $<0.001$ \\
\hline Systolic heart murmur & $86(57)$ & $60(49)$ & $26(87)$ & $<0.001$ \\
\hline Diastolic heart murmur & $7(5)$ & $7(6)$ & $0(0)$ & 0.17 \\
\hline \multicolumn{5}{|l|}{ Laboratory tests } \\
\hline Haemoglobin (g/dL) & $11.5 \pm 1.9$ & $11.5 \pm 1.7$ & $11.4 \pm 2.4$ & 0.11 \\
\hline HIV positive & $36(24)$ & $26(21)$ & $10(36)$ & 0.17 \\
\hline NTProBNP* (median, range) & $629.3(130-6400)$ & $459.6(130-4885)$ & $1589.9(130-6400)$ & $<0.0001$ \\
\hline Log NTProBNP & $6.38 \pm 1.04$ & $6.15+0.98$ & $7.16+0.89$ & $<0.0001$ \\
\hline \multicolumn{5}{|l|}{ ECG, $n(\%)$} \\
\hline Sinus rhythm & $127(83)$ & $103(84)$ & $24(86)$ & 0.79 \\
\hline Sinus tachycardia & $13(9)$ & $8(7)$ & $5(17)$ & 0.09 \\
\hline Atrial fibrillation & $1(1)$ & $1(3)$ & $0(0)$ & 0.34 \\
\hline \multicolumn{5}{|l|}{ Echocardiogram } \\
\hline $\operatorname{LVEDD}(\mathrm{mm})$ & $50.6 \pm 8.5$ & $48.6 \pm 7.7$ & $58.7 \pm 6.5$ & $<0.0001$ \\
\hline $\operatorname{LVESD}(\mathrm{mm})$ & $36.9 \pm 10.1$ & $33.4 \pm 7.6$ & $50.4 \pm 6.9$ & $<0.0001$ \\
\hline $\operatorname{EF}(\%)(n=62)$ & $51.1 \pm 13.0$ & $54.5 \pm 12.4$ & $44.7 \pm 11.8$ & 0.003 \\
\hline \multicolumn{5}{|c|}{ Medications at baseline visit, $\mathrm{n}(\%)$} \\
\hline ACE inhibitor & 5 & 0 & 5 & - \\
\hline Aldosterone antagonist & 1 & 0 & 1 & - \\
\hline Aspirin & 3 & 3 & 0 & - \\
\hline Beta blocker & 10 & 9 & 1 & - \\
\hline Bromocriptine & 5 & 0 & 5 & - \\
\hline Calcium channel blocker & 7 & 6 & 1 & - \\
\hline Digoxin & 1 & 1 & 0 & - \\
\hline Hydralazine & 1 & 1 & 0 & - \\
\hline Nitrate & 0 & 0 & 0 & - \\
\hline Furosemide & 34 & 18 & 16 & - \\
\hline Thiazide & 16 & 15 & 1 & - \\
\hline Warfarin & 9 & 9 & 0 & - \\
\hline
\end{tabular}

${ }^{*}$ NTproBNP measurements were only performed in 110 patients.

DBP, diastolic blood pressure; LVESD, left ventricle in end-systolic diameter; LVEDD, left ventricle in end-diastolic diameter; NYHA FC, New York Heart Association Functional Class; SBP, systolic blood pressure; ACE inhibitor, angiotensin-converting-enzyme inhibitor.

leading to admission in $20 \%$ of cases. At last follow-up, $11 \%$ of the patients were in NYHA functional class III or IV.

Of the 30 patients diagnosed postpartum, 3 died before their 6-month visit. Of the remaining patients, $44 \%$ felt minimally to moderately better, $12 \%$ unchanged, $44 \%$ minimally or moderately worse compared with first presentation.

\section{Obstetric and fetal outcome}

The mean gestational stage was $36.7 \pm 4.2$ with a significantly longer gestational period in women presenting with antenatal cardiac disease versus presentation postpartum $(p=0.04)$. There was a high overall rate of operative delivery with 46 of 152 women (30\%) having had a caesarean section. There were no significant differences between the different modified WHO class disease categories (II-IV) in terms of obstetric outcome. In addition to their structural CVD, 11 patients developed gestational hypertension while pregnant. Preeclampsia was found in 1:30 nullipara and 1:60 multiparous women ( $n=3$ in this cohort).

Perinatal death occurred in $1 / 152(0.66 \%, 95 \%$ CI $(0.00$ to 1.94)) due to one fetal death, translating to a perinatal mortality 
Table 4 Maternal mortality in women with structural heart disease

\begin{tabular}{|c|c|c|c|c|c|c|c|c|}
\hline Diagnosis & $\begin{array}{l}\text { Timing of } \\
\text { presentation }\end{array}$ & $\begin{array}{l}\text { Modified WHO } \\
\text { class }\end{array}$ & $\begin{array}{l}\text { NYHA } \\
\text { class }\end{array}$ & $\begin{array}{l}\text { Age } \\
\text { (years) }\end{array}$ & $\begin{array}{l}\text { EF } \\
(\%)\end{array}$ & When & Reason & Fetal outcome \\
\hline $\begin{array}{l}\text { PPCM with subsequent } \\
\text { pregnancy }\end{array}$ & Prepartum & IV & ॥ & 24 & 45 & $\begin{array}{l}61 \text { days } \\
\text { postpartum }\end{array}$ & Sudden death & Fetal survival \\
\hline PPCM & Postpartum & IV & II & 32 & 32 & $\begin{array}{l}130 \text { days } \\
\text { postpartum }\end{array}$ & $\mathrm{CCF}$ & Fetal survival \\
\hline Rheumatic HD with DVR & Prepartum & IV & I & 19 & 30 & $\begin{array}{l}50 \text { days } \\
\text { postpartum }\end{array}$ & $\begin{array}{l}\text { Valve } \\
\text { thrombosis }\end{array}$ & Fetal survival \\
\hline PPCM & Postpartum & IV & III & 24 & 24 & $\begin{array}{l}122 \text { days } \\
\text { postpartum }\end{array}$ & CCF & Fetal survival \\
\hline Familial CMO & Prepartum & IV & ॥ & 43 & 30 & $\begin{array}{l}44 \text { day } \\
\text { spostpartum }\end{array}$ & CCF & Fetal survival \\
\hline PPCM & Prepartum & IV & ॥ & 32 & 25 & $\begin{array}{l}95 \text { days } \\
\text { postpartum }\end{array}$ & Sudden death & Fetal survival \\
\hline Familial CMO & Prepartum & IV & III & 25 & 26 & $\begin{array}{l}92 \text { days } \\
\text { postpartum }\end{array}$ & CCF & Fetal survival \\
\hline PPCM post miscarriage & Postpartum & IV & IV & 24 & 31 & 150 postpartum & CCF & $\begin{array}{l}\text { Miscarriage } 20 \\
\text { weeks }\end{array}$ \\
\hline Rheumatic HD with MVR & Prepartum & IV & I & 25 & 60 & $\begin{array}{l}16 \text { weeks } \\
\text { prepartum }\end{array}$ & SBE & Fetal death \\
\hline
\end{tabular}

of $7 / 1000$ live births. In addition, there were two medically indicated terminations and two miscarriages.

Mean birth weight for the entire cohort was 2850.8 $\pm 552.7 \mathrm{~g}$, with $33 / 148$ born weighing $<2500 \mathrm{~g}$ and $46 / 148$ born preterm ( $<37$ weeks' duration).

Of 152 babies, 19 had an Apgar score of $<7$ at $5 \mathrm{~min}$. Women presenting with cardiac disease postpartum had a greater proportion of neonates who had lower Apgar scores (30\% vs $8 \% ; p=0.001)$. There were no significant differences between modified WHO groups in terms of neonatal outcome.

\section{Predictors of poor maternal outcome}

In the univariate logistic regression analysis, increased heart rate $(p=0.009)$, increased log NTproBNP $(p=0.001)$, lower income $(\mathrm{p}=0.005)$, more severe NYHA FC at baseline (class I+II vs III +IV: $\mathrm{p}=0.048)$ and decreased EF $(\mathrm{p}<0.0001)$ predicted poor outcome. In multivariate analysis, only the echocardiography EF prevailed as an independent predictor of poor outcome $(p<0.0001: \mathrm{OR}=0.93$ (0.90 to 0.96$))$, after adjusting for age, $\mathrm{HR}$, systolic blood pressure, log NTproBNP, income, level of education, HIV status, WHO class and NYHA FC at baseline.

\section{DISCUSSION}

A number of registries on women with heart disease in pregnancy have been reported in the past. ${ }^{7-10}$ However, they are predominantly from the developed world with a focus on women presenting with operated CHD. ${ }^{9}{ }^{10}$ They, therefore, do not cover the entire burden of CVD in pregnancy particular to an African population. This study evaluated the clinical outcome, based upon a referral algorithm deemed practical and appropriate for the local clinical service, in which patients often do not have prediagnosed illness because they have poor access to healthcare outside of pregnancy and are referred to a tertiary service only late in their disease due to a lack of awareness of cardiac symptoms by both patients and primary healthcare nurses. A weekly clinic with a senior cardiologist and obstetrician allowed speedy assessment of complex cases and appropriate workup, including evaluation by an anaesthetist prior to delivery and prenatal evaluation of the fetus.

The study has shown a disease pattern markedly different to that seen in the developed world with RHD, cardiomyopathies and CHD, some previously not diagnosed, being major problems, often complicated by HIV/AIDS as a comorbidity.

The data presented demonstrate a significantly higher maternal mortality rate with nine of 152 cases $(5.9 \%)$ compared with $1 \%$ in a recent study performed by ESC. ${ }^{7}$ Interestingly, most of the deaths were attributable to different forms of cardiomyopathies, with only two being related to complications attributable to sepsis and thrombosis affecting prosthetic heart valves. These observations are relevant to the general pattern of maternal mortality described in South. The confidential inquiry into maternal death in South Africa reported that, of the 4867 death reported over 2 years, 14\% were due to hypertensive disorders, with another $8.8 \%$ due to medical and surgical conditions. ${ }^{11}$ The definitions employed describe maternal death as death occurring during pregnancy or within 42 days of delivery as it is international standard. ${ }^{12}$ The definition of death within 42 days applied to our data would have completely underestimated the number of cardiac deaths related to pregnancy because eight out of nine deaths would not have been captured. Our data suggest that care needs to be stepped up covering the postpartum period with earlier referral to the general cardiac or cardiomyopathy clinic and adequate counselling about the risks of future pregnancy and contraceptive services be provided. Our findings are likely to be applicable to other regions where cardiomyopathies due to a number of conditions are common. ${ }^{13} 14$

A recent systematic review of the burden of antenatal heart disease in South Africa reported a prevalence of heart disease, ranging from 123 to 943 per 100000 deliveries with RHD being the most common abnormality, followed by cardiomyopathies. ${ }^{15}$ The results of the Global Burden of Disease Study 2013 on global, regional and national levels and causes of maternal mortality during 1990-2013, published in 2014, reported on an ongoing high maternal mortality in South Africa, with 171.5/100 000 live births. ${ }^{16}$ Although substantial progress has been made, South Africa will not meet the fifth 
Millennium Developmental Goal. Heart disease, chronic hypertension and preeclampsia contributed to more than $20 \%$ of 3024 cases with severe maternal outcome in the WHO Multicountry Survey on maternal and newborn health. ${ }^{17}$

In addition to the high number of postnatal deaths, our data showed that $18 \%$ of women who survived and attended follow-up clinics had symptoms that were worse after the pregnancy, with $44 \%$ having moderate-to-severe disability. There were no discriminating criteria according to diagnosis that allowed any prediction of who would become more symptomatic, although the EF was significantly worse in the cardiomyopathy group.

The obstetric outcome for the cohort studied was good. There were no stillbirths and only one neonatal death. Although $30 \%$ of the patients delivered before 37 weeks, the mean gestational age at delivery fell just short of 37 weeks and the mean birth weight was $2.85 \mathrm{~kg}$. There was a high rate of obstetric intervention evident as a $30 \%$ caesarean section rate, similar to the $27 \%$ in the Canadian CARPREG study ${ }^{8}$ and $41 \%$ in the European cohort. ${ }^{7}$ In addition, one in five pregnancies required hospitalisation for cardiac assessment and treatment during the course of the pregnancy.

The perinatal outcome in an environment of intensive surveillance and management was found to be generally good. This has to be seen in the context of a high overall perinatal mortality of 34/1000 live births in South Africa. ${ }^{11}$

With regards to the clinical service provision, a large proportion of the women studied had RHD due to the sequelae of group A streptococcal infection. These women all benefit from access to clinics such as the Cardiac Disease and Maternity Clinic (CDMC), where multidisciplinary care contributes to the likelihood of safe motherhood. In the future, echocardiographybased screening of patients may further improve identification and referral of high-risk cases, although the cost-effectiveness of this intervention is yet to be established. ${ }^{18}{ }^{19}$ B-type natriuretic peptides have also been shown to be effective biomarkers in

\section{Key messages}

\section{What is already known on this subject?}

A number of registries on women with heart disease in pregnancy have been reported in the past years. However, they are predominantly from the developed world with a focus on women presenting with operated congenital heart disease.

\section{What might this study add?}

We report on 225 women with heart disease in pregnancy. We found a disease pattern markedly different to that in the higher-income countries. Rheumatic heart disease, cardiomyopathy and hypertensive heart failure are major problems often complicated by HIVIAIDS as comorbidity.

\section{How might this impact on clinical practice?}

Joint obstetric-cardiac care showed survival rate of mothers presenting while pregnant, even those with complex diseases similar to that seen in the western world, but also that of their offspring. However, high mortality occurred in the postpartum period. As traditionally maternal mortality is reported as death $<42$ days postdelivery, eight of nine deaths would have not been recorded as maternal death, which could imply underreporting of maternal deaths in the context of an overall very high maternal death rate in South Africa. pregnant women, correlating with outcome, ${ }^{20}$ and need further exploration as a bed-side test in the developing world.

\section{LIMITATIONS}

This study has several limitations as it is an observational study confined to a particular area. The data are therefore at variance with the previously published literature. In addition, women with subclinical disease, milder forms of CVD or fatal events prior to admission were not captured. Only M-mode echocardiography has been performed to qualify left ventricular function in a number of cases. We have adhered to the published STROBE guidelines relating to reporting of this type of study. ${ }^{21}$

\section{CONCLUSION}

Our data show a disease pattern in South Africa, markedly different to that of the developed world. Joint obstetric-cardiac care is associated with excellent survival rates of mothers presenting while pregnant, even with complex diseases, and their offspring. The greatest risk of adverse outcome is attributable to late presentation and left ventricular failure with death commonly occurring outside the 42-day maternal mortality reporting period. The perinatal outcome in an environment of intensive surveillance and management was found to be generally good.

\section{Author affiliations}

${ }^{1}$ Department of Medicine, Faculty of Health Sciences, Hatter Institute for Cardiovascular Research in Africa, University of Cape Town, Cape Town, South Africa

${ }^{2}$ Faculty of Health Sciences, Inter-Cape Heart MRC Unit and Institute of Infectious Diseases and Molecular Medicine, University of Cape Town, Cape Town, South Africa

${ }^{3}$ Division of Cardiology, Department of Medicine, Groote Schuur Hospital, University of Cape Town, Cape Town, South Africa

${ }^{4}$ Faculty of Health Sciences, School of Clinical Medicine, University of the

Witwatersrand, Johannesburg, South Africa

${ }^{5}$ Division of Obstetrics and Gynaecology, Groote Schuur Hospital, University of Cape Town, Cape Town, South Africa

${ }^{6}$ Department of Paediatrics, Red Cross War Memorial Children's Hospital and University of Cape Town, Cape Town, South Africa

${ }^{7}$ Division of Infectious Diseases and HIV Medicine, Department of Medicine, Groote Schuur Hospital, University of Cape Town, Cape Town, South Africa

${ }^{8}$ Department of Cardiology, Thoraxcenter, Erasmus Medical Center, Rotterdam, The Netherlands

Acknowledgements The authors would like to acknowledge the support of Mrs Sylvia Dennis, Hatter Institute for Cardiovascular Research in Africa, in preparing the manuscript. This research could not have been conducted without the funding support of The University of Cape Town, the Medical Research Council South Africa, the Medtronic Foundation, Maurice Hatter Foundation and Servier. We also would like to thank Dr Lori Blauwet and Dr Laetitia Aquah, Mayo Clinic, Rochester, USA, and other physicians and nurses at the Department of Cardiology and Obstetrics for their support.

Contributors KS, CE, FT and JA have participated in the original conception and design of the study. EL was fundamentally involved in the data analysis and interpretation. $\mathrm{LZ}, \mathrm{AO}, \mathrm{JR}-\mathrm{H}$ and $\mathrm{TL}$ have participated in the interpretation of the data, drafting and critical revision of the paper. KS takes responsibility for the overall content as guarantor.

Funding University of Cape Town, South Africa.

\section{Competing interests None.}

Ethics approval Human Ethics Committee, University of Cape Town.

Provenance and peer review Not commissioned; externally peer reviewed.

Open Access This is an Open Access article distributed in accordance with the Creative Commons Attribution Non Commercial (CC BY-NC 4.0) license, which permits others to distribute, remix, adapt, build upon this work non-commercially, and license their derivative works on different terms, provided the original work is properly cited and the use is non-commercial. See: http://creativecommons.org/ licenses/by-nc/4.0/ 


\section{REFERENCES}

1 Mocumbi AO, Sliwa K. Women's cardiovascular health in Africa. Heart 2012;98:450-5.

2 Sliwa K, Mayosi BM. Recent advances in the epidemiology, pathogenesis and prognosis of acute heart failure and cardiomyopathy in Africa. Heart 2013;99:1317-22.

3 Sahn DJ, Demaria A, Kisslo J, et al. Recommendations regarding quantitation in M-Mode echocardiography: results of a survey of echocardiographic measurements. Circulation 1978;58:1072-83.

4 Regitz-Zagrosek V, Blomstrom Lundqvist C, Borghi C, et al. ESC Guidelines on the management of cardiovascular diseases during pregnancy: the Task Force on the Management of Cardiovascular Diseases during Pregnancy of the European Society of Cardiology (ESC). Eur Heart J 2011;32:3147-97.

5 Blauwet LA, Libhaber E, Forster 0 , et al. Predictors of outcome in 176 South African patients with peripartum cardiomyopathy. Heart 2013;99:308-13.

6 Prickett TC, Yandle TG, Nicholls MG, et al. Identification of amino-terminal pro-C-type natriuretic peptide in human plasma. Biochem Biophys Res Commun 2001;286:513-17.

7 Roos-Hesselink JW, Ruys TP, Stein Jl, et al. Outcome of pregnancy in patients with structural or ischaemic heart disease: results of a registry of the European Society of Cardiology. Eur Heart J 2013;34:657-65.

8 Siu SC, Sermer M, Colman JM, et al. Prospective multicenter study of pregnancy outcomes in women with heart disease. Circulation 2001;104:515-21.

9 Pieper PG, Balci A, Aarnoudse JG, et al. Uteroplacental blood flow, cardiac function, and pregnancy outcome in women with congenital heart disease. Circulation 2013;128:2478-87.

10 Stangl V, Schad J, Gossing G, et al. Maternal heart disease and pregnancy outcome: a single-centre experience. Eur J Heart Fail 2008;10:855-60.

11 NCCEEMD. National Committee for the Confidential Enquiries into Maternal Death (NCCEMD) in South Africa. 2012. http://wwwdohgovza/docs/reports/2012/Report
12 World Health Organization. Maternal mortality in 2005: estimates developed by WHO, UNICEF, UNFPA, and the World Bank. ISBN 978924159621 3. 2007.

13 Sliwa K, Hilfiker-Kleiner D, Petrie M, et al. Current state of knowledge on aetiology, diagnosis, management, and therapy of peripartum cardiomyopathy: a position statement from the Heart Failure Association of the European Society of Cardiology Working Group on Peripartum Cardiomyopathy. Eur Heart $J$ 2010;12:767-78.

14 Sliwa K, Hilfiker-Kleiner D, Mebaaza A, et al. EURObservational Research Programme: a worldwide registry on peripartum cardiomyopathy (PPCM) in conjunction with the Heart Failure Association of the European Society of Cardiology Working Group on PPCM. Eur J Heart Fail 2014;16:583-91.

15 Watkins DA, Sebitloane M, Engel ME, et al. The burden of antenatal heart disease in South Africa: a systematic review. BMC Cardiovasc Disord 2012;12:23.

16 Kassebaum NJ, Bertozzi-Villa A, Coggeshall MS, et al. Global, regional, and national levels and causes of maternal mortality during 1990-2013: a systematic analysis for the Global Burden of Disease Study 2013. Lancet 2014. doi:10.1016/ S0140-6736(14)60696-6. [Epub ahead of print 2 May 2014]

17 Souza JP, Gulmezoglu AM, Vogel J, et al. Moving beyond essential interventions for reduction of maternal mortality (the WHO Multicountry Survey on Maternal and Newborn Health): a cross-sectional study. Lancet 2013;381:1747-55.

18 Mayosi BM, Flisher AJ, Lalloo UG, et al. The burden of non-communicable diseases in South Africa. Lancet 2009:374:934-47.

19 Sliwa K, Zilla P. Rheumatic heart disease: the tip of the iceberg. Circulation 2012;125:3060-2.

20 Tanous D, Siu SC, Mason J, et al. B-type natriuretic peptide in pregnant women with heart disease. J Am Coll Cardiol 2010;56:1247-53.

21 von Elm E, Altman D, Egger M, et al. STROBE Initiative. The Strengthening the Reporting of Observational Studies in Epidemiology (STROBE) statement: guidelines for reporting observational studies. Bull World Health Organ 2007;85:867-72. 